simply be replaced by a better one? Why live a parsimonious and careful life if the miracle of medical technology provides an alternative?

Technology steps in after the damage has been done, at a far greater cost to society but at much more dramatic level. As long as these values are held in our society, as long as popular culture continues both to reflect and to reproduce these values, public health practitioners will be seen as spoilsports, not saints.

1 Galtang J, Rougue M. Structuring and selecting news. In: Cohen S, Young Y, eds. The manufacture of news: sacial problems, deviance and mass media. London: Constable, 1973:62-72.

2 Bates E, Lapsley H. The health machine: the impact of medical technology. Ringwood: Penguin, 1985.

3 McLaughlin J. The doctor shows. Fournal of Communication 1975;25:182-4

4 Chapman S. Advertising and psychotropic drugs: the place of myth in ideological reproduction. Soc Sci Med 1979;13A:751-64.
5 Turow J, Playing doctor: television, storytelling and medical power. New York: Oxford University Press, 1989.

6 Gerbner G, Gross L, Morgan M, Signorrielli N. Health and medicine on television. N Englf Med 1981;305:901-4.

7 Krantzler NJ. Media images of physicians and nurses in the United States. oc Sci Med 1986;22:933-52.

8 Karpf A. Doctoring the media: the reporting of health and medicine. London Routledge, 1988.

9 Stein HF. American medicine as culture. Colorado: Westview, 1990

10 Helman C. Heart disease and the cultural construction of time: the type A W behaviour pattern as a western culture-bound syndrome. Soc Sci Med 1987;25:969-79.

11 Pfund N, Hofstader L. Biomedical innovation and the press. Fournal of $\overrightarrow{\overline{\vec{N}}}$

Hall JP, Heller RF, Dobson AJ, Lloyd DM, Sanson-Fisher RW, Leeder SR. A cost-effectiveness analysis of alternative strategies from the prevention of heart disease. Med $\mathcal{F}$ Aust 1988;148:273-7.

13 Turow J, Coe L. Curing television's ills: the portrayal of health care. Fournal of $\overline{\bar{\sigma}}$ Communication 1986;35:36-51.

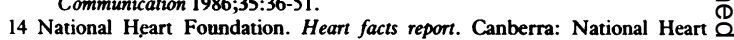
Foundation, 1988:13.

15 Goldman L, Cook EF. An analysis of the comparative effects of medical $\tilde{\omega}$ interventions and changes in lifestyle. Ann Intern Med 1984;101:825-36.

\title{
Changing the hideous face of war
}

\section{B J S Grogono}

Besides the thousands killed in war, millions are crippled or hideously deformed. During the first world war the British army developed improved medical services to cope with the enormous number of casualties from the incessant bombardments and furore of trench warfare. Under the guidance of Sir Robert Jones $^{12}$ a comprehensive management of injuries was established. After initial treatment in the field clearing station the wounded soldier was transferred to a base hospital for more definitive care and the extent of his injuries was assessed. He was then sent back to "blighty," where he received skilled treatment, finally arriving at a rehabilitation hospital. The centre at Shepherd's Bush, London, managed severe skeletal injuries, nerve lesions, and orthopaedic problems; hand injuries and amputation received special attention. A young army doctor, Harold Delf Gillies, saw that specialised management of facial and maxillary injuries was needed. He was a New Zealander who had specialised in ear, nose, and throat surgery and could see the urgent need to segregate the soldiers with these wounds from the rest of the casualties.

The young captain Gillies was not familiar with the classic work of Tagliocozzi, ${ }^{4}$ who had described the use of pedicle grafts for the repair of amputated noses in the sixteenth century, but he did encounter Charles
Auguste Valadier, a dental specialist to the officers of the imperial staff, who repaired jaw defects by using tissue, such as bone, from other parts of the body. N Gillies and Valadier operated together, and it was this baptism into the realm of faciomaxillary injuries that inspired Gillies. He was lent a book on these injuries written by a German surgeon, Lindeman; he visitedo Hippolyte Morestin, the most famous plastic surgeon ${ }^{-}$ in Europe; and he persuaded the medical authorities ofe the need for special centres for treating faciomaxillary. injuries. The authorities included Sir Alfred Keogh, director general of the army medical services, and广 Sir William Arbuthnot Lane, one of the most distinguished surgeons in England.

Within a year the Cambridge Hospital at Aldershoto was opened and Gillies was assigned special duties as plastic surgeon. So that soldiers with facial injuries? were sent to ' is new unit Gillies bought $£ 10$ worth of labels sayin "Faciomaxillary injury-Cambridge Hospital, Aldershot" and sent them to the field. hospitals in France to be pinned to the casualty's chest

In January 1916 the first naval casualties arrived followed shortly afterwards by 2000 injured soldiersi? from the battle of the Somme. Day after day, nigh? after night they came with half their faces or jaws shoto away. Suffocation, sepsis, gangrene, and haemorrhage
Halifax, Nova Scotia, Canada B3H 1 G3 B J S Grogono, FRCS, retired orthopaedic surgeon

Correspondence to: Mr B J S Grogono, 5854 Gorsebrook Ave, Halifax, Nova Scotia, Canada B3H 1 G3.

BMf 1991;303:1586-8

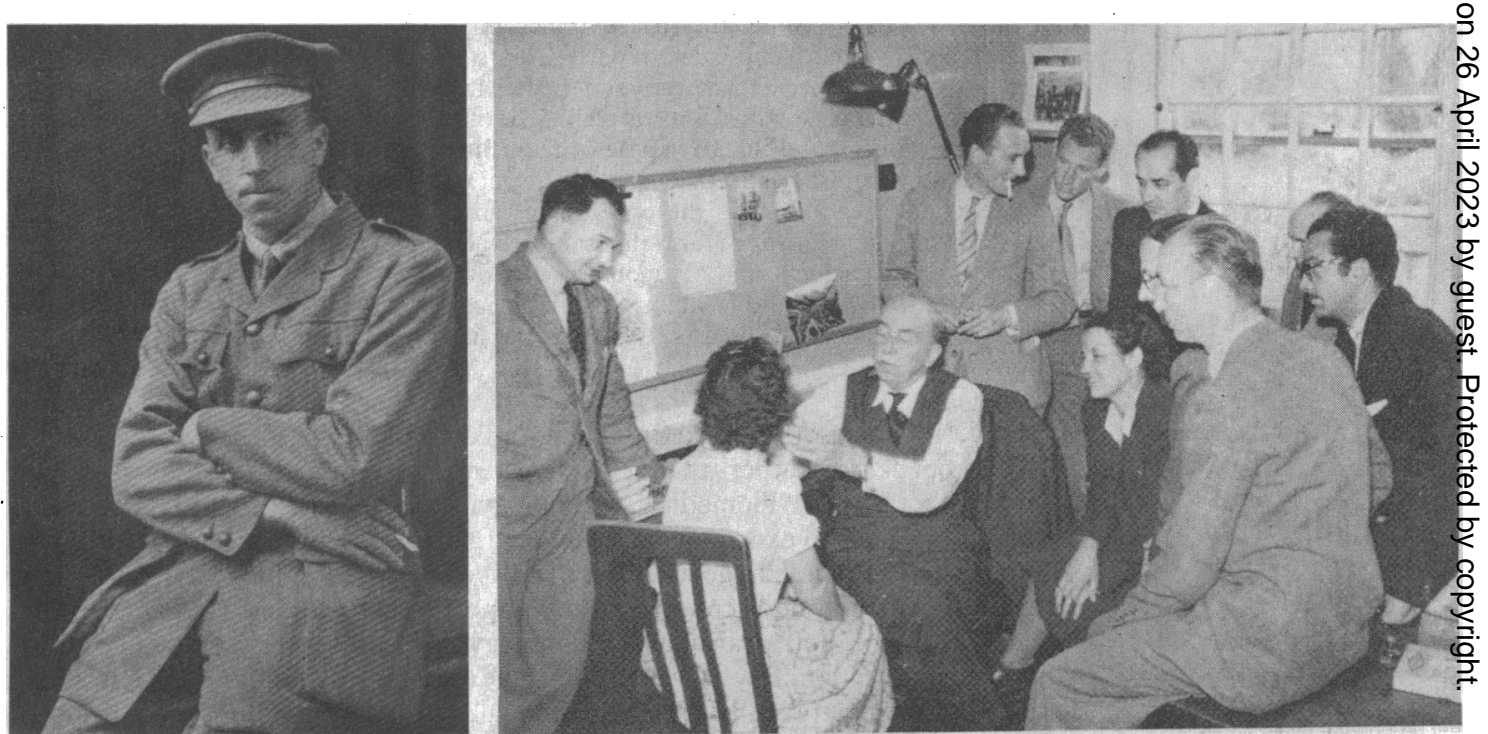

(Left) Major H D Gillies as a medical officer, working with the Red Cross, 1915; (right) Sir Harold Gillies teaching at Rooksdown House, 1944. Photographer unknown; from R Pound, "Gillies, surgeon extraordinary."' 


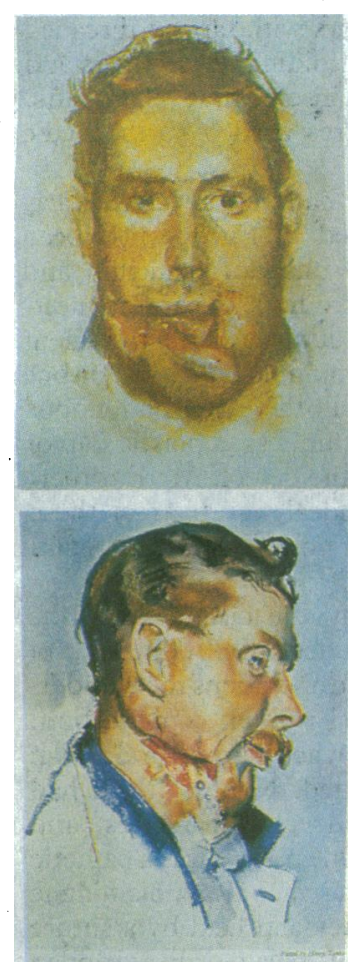

Tube pedicle-one of the first of Gillies's operations were constant threats. Cries of "Kill me, kill me" were often heard from the new arrivals. ${ }^{5}$ Slowly, calmly, compassionately, Harold Gillies tackled the enormous task of treating these soldiers.

Following the tradition of surgeons in Italy and India, Gillies developed techniques using skin flaps to reconstruct noses, mouths, eyelids, and ears. He used bone grafts taken from ribs to fill bone defects in the jaw and originated many procedures for complex repairs.

Gillies ensured that all these injuries and operations were recorded. He sketched out his procedures and the artist Henry Tonks ${ }^{6}$ contributed many pastel drawings. Photography was also important. In the first world war Sidney Walridge mastered the art of recording this appalling but historic stage of war surgery, which was perfected in the second world war by Percy Hennel.

\section{The unit moves to Sidcup}

The Cambridge Hospital, Aldershot, soon became overcrowded and a new hospital - the Queen's Hospital, Sidcup, Kent-was opened in August 1917. It had 600 beds, operating rooms, and $x$ ray department, a photographic unit, and a studio for Henry Tonks. It was here that Gillies conceived the idea of a tubed pedicle graft (figure). Converting the pedicle flap into a tube enabled skin from distant sites to be transposed to fill defects elsewhere. This major breakthrough in reconstructive surgery remained the most commonly used method for replacing lost tissue until 1974, when Daniels and Taylor invented free transfer by using microvascular anastomosis. ${ }^{8}$

The Queen's Hospital, Sidcup, became internationally renowned. By the end of hostilities in 1918, 11572 major facial operations had been performed. Visiting surgeons from Australia, New Zealand, Canada, and the United States were able to take home the invaluable expertise they had gained in this type of surgery. After the first world war Gillies was knighted for his contributions, and he returned to civilian practice to continue the development of plastic surgery. But by 1939, when the prospect of large numbers of faciomaxillary injuries loomed once again, there were still only four plastic surgeons in England. Once again Gillies set about organising hospitals.

In the last week of May 1944, when my twin brother and I were medical students at St Mary's Hospital, Paddington, our formal clerkships in the dingy basement outpatient department were interrupted and we were transferred to the emergency medical service hospital at Park Prewitt near Basingstoke. Normally a thousand bedded mental hospital, it had been evacuated and transformed into a centre for the

Tonks. Reproduced by permission of the president and council of the Royal College of Surgeons of England

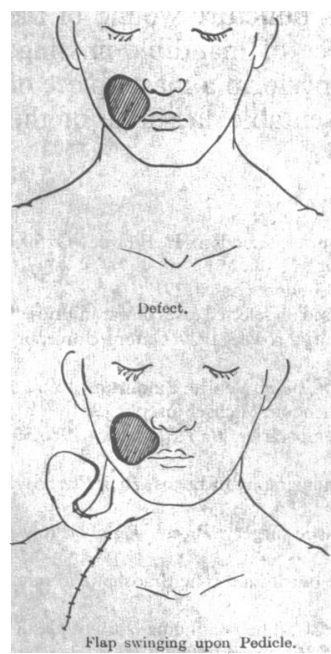

treatment of casualties from the "second front." Casualties were transferred from the beaches of France and battle sites of Europe to trains in England to base hospitals near their homes. Each train carried nearly a thousand wounded, and after triage those with faciomaxillary injuries were segregated from the mass of general casualties admitted to the main part of the hospital. Rooksdown House was a separate wing of the hospital and dealt mainly with faciomaxillary injuries and burns, under the guidance of Gillies.

This country mansion was by no means ideally designed for a surgical unit. It had three floors with beds on each floor, narrow corridors, winding stairways, and no lift. A suite of operating rooms had been carved out from the administrative block, and a special burns unit installed, with large tubs. The wards were small and inconvenient. A small laboratory, $x$ ray facilities, an area for blood grouping, and a set of rooms for the staff completed the unit.

Besides Gillies the staff included James Cuthbert, a young surgeon from South Africa; Dr Bob Langston from Canada; and Professor Martin Rushton, a specialist in dental care for faciomaxillary injuries. Dr Patrick Shackleton was the chief anaesthetist and general physician. Related to $\mathrm{Dr}$ Shackleton of Antarctic fame, he ensured a high standard of clinical care, and his warm personality kept everyone on an even keel in a time of crisis. Anaesthetics had come a long way since the early days of administering open ether, thanks to Magill's development of endotracheal intubation with an electrically lighted laryngoscope. "Shack," as he was affectionately known, was a master of this technique, which he supplemented when necessary with bronchoscopy, thus saving many patients from pulmonary complications.

There were other plastic surgeons from centres around the world who had come to study at this unique centre. Altogether 34 countries were represented. Shifts ran from $8 \mathrm{am}$ to $8 \mathrm{pm}$, seven days a week. Although Gillies was 62 at the time, he often, like the others, worked through the night. One night Gillies was still on duty at $8 \mathrm{pm}$. A man was admitted, two days after being injured in France, with a terrible wound to his mouth and mandible. There was a considerable defect of skin on his cheek and Gillies spent the whole night constructing a rotation flap of skin based on the temperomaxillary artery, which he swung down as a primary repair.

\section{A vision of misery and mercy}

My first assignment in the burns unit, was to keep the blood transfusions flowing, set up the drips, and 0 take blood specimens night and day. I can still feel the impact of the burns ward - a vision of human suffering and disfigurement, of misery and mercy. My first $\frac{D}{0}$ impression was of grotesquely deformed and scarred faces. Many of the blinded soldiers were Italian, $\mathbb{N}$ transferred from the Italian campaign. "There is no need for such victims to become blind," explained Mr O Cuthbert as we toured round the beds. "Most of the 0 burns are second and third degree, and do not initially affect the orbit. It's only secondary infection that results in blindness. Careful irrigation of the eyes and $T$ repair of the burned lids will usually preserve sight."

Next to the ward was the saline bath area. The idea $\cong$ was that after initial treatment of the burns the necrotic $\stackrel{\mathbb{8}}{\circ}$ tissue could be separated by totally immersing the $\sigma$ soldier in a tub of isotonic saline. Even now I can recall the smell of fried flesh, the misery and bravery of patients as the vaseline gauze was tediously removed. Once a granulating area had been achieved skin grafting began. Operating lists extended for hours as the surgeons took grafts with a straight blade or a Humby knife, cutting the delicate veil of epithelium 


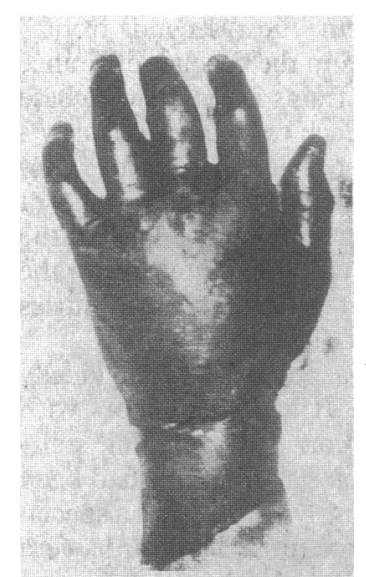

Tannic acid hand: tissues have congealed to produce stiff, useless fingers

Sketch by Henry Tonks of Harold Gillies operating, 1917. Reproduced by permission of the president and council of the Royal College of Surgeons of England

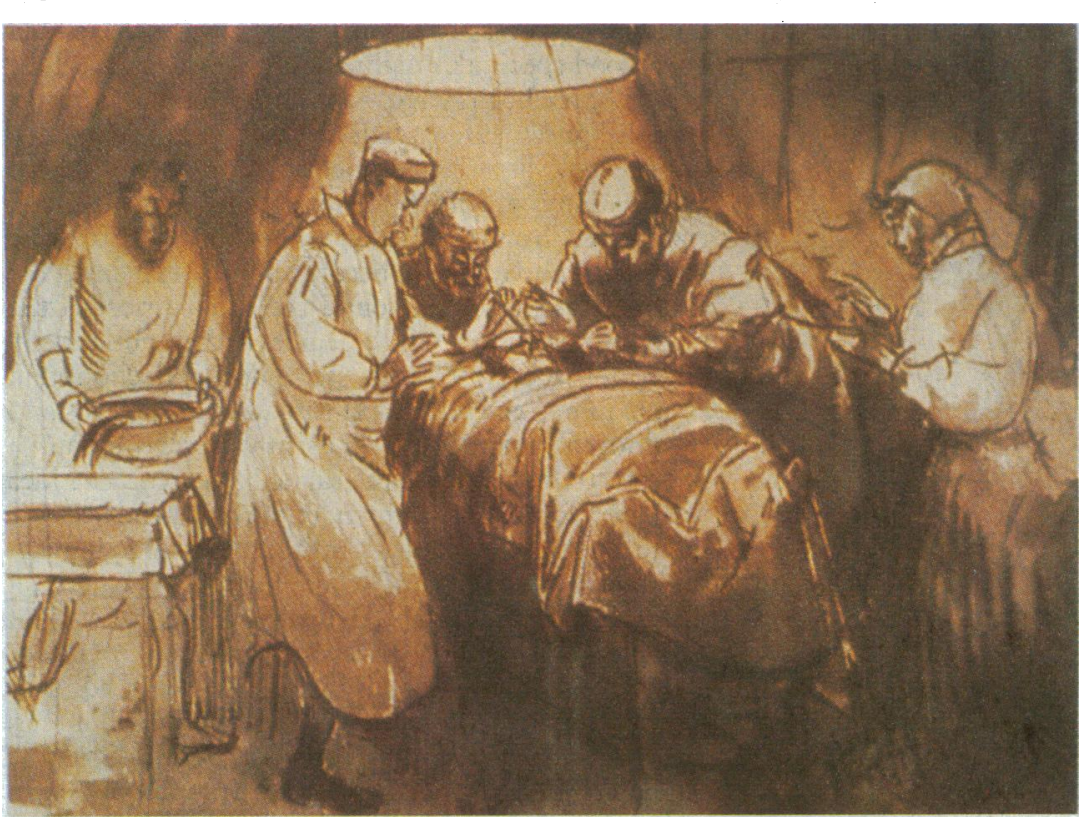
which had usually been spared in these patients. Plasma was given freely to replace the lost tissue proteins and was always available. It came in glass bottles as a yellow powder; the right quantity of saline would be added for the single or double strength mixture. As the mixture required much shaking I went to the dental department, attached my bottles to the foot pump of an old dentist's drill, and connected this up to a motor. The contraption looked like something found in paint shops today.

After a spell in the burns unit I was exposed to these injuries was extremely complex: the bone architecture had to be assessed and reconstruction carefully planned. A dental team led by Dr Rushton and Dr Walker worked closely with the plastic surgeons. Dental impressions and splints were used to support the framework of the injured maxilla and mandible, and external fixators with tapped threaded pins were used to form a scaffolding of steel bars and provide a stable base for the insertion of bone grafts. This was similar to procedures used by orthopaedic surgeons 40 years later.

Unlike the Italians, who had not received early treatment, the British injured in Europe had been given an injection of 30000 units of penicillin and proper debridement of their wounds. A card delineating the exact location of the wounds and the treatment given was attached to each wounded soldier. For one man hand injuries, in which all the extensor tendons were exposed with overlying skin loss, a plastic flap of skin had been used to cover the defect. Mr Cuthbert was delighted: "That is the ideal way to treat these injuries, as the tendons will remain intact and retain their sliding motion."

We were all impressed by the cleanness of the wounds and the wonderful effect of 30000 units of penicillin, which allowed these operations to be undertaken and the wounds to heal without complication. This was brought home to us when a group of German prisoners of war were admitted. None of them had received penicillin, most had ersatz bandages, and their wounds were unclean. One patient was a pathetic sight. His whole mandible was shot away, his tongue was held out from the vacancy and held by a suture from falling back onto his soft palate, saliva dripped $ᄋ$ constantly from his open mouth, and a tracheostomy prevented him from suffocating. Gillies, Mr Cuthbert, and the indomitable Dr Shackleton tackled the problem suturing the mucosal surfaces together, and somehow the vast gap in his mandible was replaced. After months of skilled treatment a new face had been created. ${ }^{10}$ patients with faciomaxillary injuries. The analysis of

\section{A haven and a hero}

For the most part Rooksdown House was a peaceful haven. Set in the countryside, it seemed a long way from the battlefields, and the bombs usually passed us by on their way to London. The doodlebugs didn't bother us very often, but one day, while Gillies was peacefully perfecting one of his miracles and Dr Shackleton was immersed in the function of his Magill's apparatus, we heard the familiar buzz of the doodlebug. Then suddenly, silence. Its motors had stopped, indicating an imminent landing and explosion. I remember descending rather closer to the site where I was endeavouring to ensure a good blood supply, while Gillies, the anaesthetist, and the nurses $\dot{\delta}$ paused for an instant. With a bang the bug exploded in a field some distance away, harmlessly.

Sir Harold was above all an artist. Eccentric, volatile, sometimes cantankerous, he had a supreme gift of $\mathcal{N}$ vision. ${ }^{10} \mathrm{He}$ could look at a grossly mangled face, $\frac{D}{2}$ shattered by shrapnel with a puncture wound of the cheek and mouth and a piece of mandible missing, $N$ assess the deficits, and then perform a masterpiece of $\mathrm{\omega}$ surgery, refashioning a presentable facsimile of the victim's true appearance.

1 Jones RJ. Orthopaedic surgery of iniuries. London: H Frowde, Oxford University Press, 1923.
Unic

2 Jones RJ. Notes on military orthopaedics. London: Cassell, 1917.

Gillies HD. Plastic surgery of the face based on selected cases of war injuries of the face including burns. London: Henry Frowde, 1920. Oxford University Press, 1920.

4 Tagliocozzi G. De curtorum chirurgia per insitonem. Venice: Bindorum, 1597.

5 Pound R. Gillies, surgeon extraordinary. London: Michael Joseph, 1964.

6 Bennett JB. Henry Tonks and his contemporaries. Br f Plast Surg 1986;39: $1-34$

Wallace AK. Early history of clinical photography of burns. Br f Plast Surg

1988;41:441-4.
8 Bennett JB. Aspects of the history of plastic surgery. Proceedings of the Royal Society of Medicine 1983;76:153.

9 McIndoe A. Total reconstruction of the burnt face. The Bradshawe lecture. $B$ F Plast Surg 1983;41:422-40.

10 Brown RF, Chapman CW, McDermot BC. The continuing story of plastic surgery in Britain's armed services. B f Plast Surg 1989;42:700-9. 